\title{
Cisplatin-induced nephrotoxicity
}

\author{
J. D. Stewart · H. M. Bolt
}

Published online: 14 June 2012

(c) Springer-Verlag 2012

Nephrotoxicity represents one of the cutting-edge topics of our journal (Francescato et al. 2011; Stewart et al. 2011a, b; Faiz et al. 2011; Briguori et al. 2011; Song et al. 2011; Abdel-Bakky et al. 2011; Liu et al. 2011; Chattopadhyay et al. 2011). Therefore, the editors are pleased that Antonio C. Santos and colleagues from the University of Sao Paulo in Brazil accepted our invitation of a state of the art review on cisplatin-induced nephrotoxicity and strategies of nephroprotection (Santos et al. 2012; this issue). Cisplatin was accidentally discovered by Barnett Rosenberg who initially intended to kill bacteria by an electric field. Later, Rosenberg recognized that cells were not killed by the electric field but by a compound released from the platinum electrodes. Interestingly, cisplatin is cytotoxic via its aquated metabolite. In blood, where chloride concentrations are relatively high, cisplatin remains unaltered. However, as soon as cisplatin enters the cell, it undergoes hydrolysis because of low intracellular chloride concentrations, and the two chloride ions are replaced by water. This aquated form binds to N7 positions of guanine and forms the intrastrand crosslinks representing the cytotoxic mechanism of cisplatin. Besides its DNA binding effect, cisplatin also causes mitochondrial damage leading to reactive oxygen species. Generation of oxidative stress together with relatively high concentrations in the renal transport system explains the preferential kidney toxicity of cisplatin. The authors give a comprehensive overview of the molecular mechanisms of cisplatin-induced toxicity in the kidney and also present the

J. D. Stewart · H. M. Bolt $(\bowtie)$

Leibniz Institut für Arbeitsforschung an der TU Dortmund, Leibniz Research Centre for Working Environment and Human Factors (IfADo), Ardeystrasse 67, 44139 Dortmund, Germany e-mail: bolt@ifado.de most efficient clinical strategies to prevent toxicity. The article is highly recommended to anyone interested in the mechanisms of nephrotoxicity.

\section{References}

Abdel-Bakky MS, Hammad MA, Walker LA, Ashfaq MK (2011) Silencing of tissue factor by antisense deoxyoligonucleotide prevents monocrotaline/LPS renal injury in mice. Arch Toxicol 85(10): 1245-1256

Briguori C, Quintavalle C, De Micco F, Condorelli G (2011) Nephrotoxicity of contrast media and protective effects of acetylcysteine. Arch Toxicol 85(3):165-173 (review. Erratum in: Arch Toxicol 2011,85(3):175)

Chattopadhyay A, Podder S, Agarwal S, Bhattacharya S (2011) Fluoride-induced histopathology and synthesis of stress protein in liver and kidney of mice. Arch Toxicol 85(4):327-335

Faiz H, Conjard-Duplany A, Boghossian M, Martin G, Baverel G, Ferrier B (2011) Cadmium chloride inhibits lactate gluconeogenesis in isolated human renal proximal tubules: a cellular metabolomic approach with 13C-NMR. Arch Toxicol 85(9): 1067-1077

Francescato HD, Marin EC, Cunha Fde Q, Costa RS, Silva CG, Coimbra TM (2011) Role of endogenous hydrogen sulfide on renal damage induced by adriamycin injection. Arch Toxicol 85(12):1597-1606

Liu YN, Wang SH, Li T, Wang Q, Tu W, Cai K, Hou XJ, Tian RM, Gao X, Liu H, Xiao L, Shi J, Cheng YG, Li JC, Wang H (2011) Shiga toxin type 2 (Stx2), a potential agent of bioterrorism, has a short distribution and a long elimination half-life, and induces kidney and thymus lesions in rats. Arch Toxicol 85(9): $1133-1140$

Neife Aparecida Guinaim dos Santos, Maria Augusta Carvalho Rodrigues, Nadia Maria Martins and Antonio Cardozo dos Santos (2012, this issue) Cisplatin-induced nephrotoxicity and targets of nephroprotection: an update. doi:10.1007/s00204012-0821-7. (review)

Song YJ, Li J, Xie XF, Wang H, Li QX (2011) Effects of amlodipine on TGF- $\beta$-induced Smad2, 4 expressions in adriamycin toxicity of rat mesangial cells. Arch Toxicol 85(6):663-668 
Stewart JD, Hengstler JG, Bolt HM (2011a) Contrast agent-induced nephrotoxicity: role of oxidative stress and apoptosis through the mitochondrial pathway. Arch Toxicol 85(3):163-164
Stewart JD, Hengstler JG, Bolt HM (2011b) Control of oxidative stress by the Keap1-Nrf2 pathway. Arch Toxicol 85(4):239 